\title{
Advocating the Need for a CT Coronary Angiography Screening Program for Prevention of Coronary Artery Disease in High - Risk Population \& guiding future pharmaceutical research
}

\author{
Abhinav Aggarwal* \\ Department of Radiology, Mata Chanan Devi Hospital, India
}

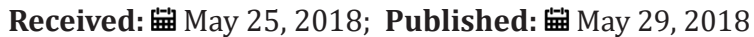

*Corresponding author: Abhinav Aggarwal, Junior Consultant Radiologist, Department of Radiology, Mata Chanan Devi Hospital, Block C, Janak Puri, New Delhi, India

\begin{abstract}
Cardio-vascular disease (CVD) is one of the major causes of morbidity and mortality in Europe and world. It accounts for majority of spend on healthcare in European Union countries and is the second on the list. Non-calcific plaques form the majority of plaques and non-calcific \& mixed plaques are responsible for majority cases of severe stenosis. Since non-calcific and mixed plaques are resolvable by intensive statin therapy and are responsible for majority of severe acute coronary related events (vulnerable plaques), coronary artery disease is preventable if proper screening is done which should lead to significant decrease in economic burden of cardio-vascular \& cerebro-vascular diseases. These findings warrant a discussion on systemic screening program for the same through CT coronary angiography.
\end{abstract}

Abbreviations: CVD: Cardio-vascular disease; EU: European Union: EHN: European Heart Network; A\&E: accident \& emergency; GPs: General practitioners; CTCA: Computed Tomography Coronary Angiography screening

\section{Introduction}

Cardio-vascular disease (CVD) is one of the major causes of morbidity and mortality in Europe and world [1]. Spectrum of cardio-vascular disease includes coronary artery disease, high blood pressure, angina, heart attack, congenital heart disease and stroke along with heart valve disease and cardiomyopathy [2]. The latest figures for 2017 issued by European Society of Cardiology show that every year 6 million new cases of CVD are introduced in European Union (EU) alone with a total of 11 million cases in whole of Europe. The figures for these have been increasing every year despite the introduction of lifestyle modifications including better diets and increasing exercise in daily routines. All these diseases lead to impairment of a large amount of man-force leading to high cost of the EU economy [3].

\section{Etiology/Disease Burden Of CVD}

Traditionally various lifestyle components like smoking, alcohol consumption and blood levels of cholesterol have been the main factors related to increased incidence of CVD [3,4]. In recent decades effect of genetic factors like overweight/obesity and diabetes have increased and is expected to increase further in coming decades $[3,5]$. As per the European Heart Network (EHN) statistics of 2015 , incidence of diabetes has increased by $50 \%$ in last ten years. Despite successful implementation of various lifestyle changes like higher consumption of vegetables \& fruits, decrease in smoking and increase in physical activity there has been an increase in incidence of CVD. This is because incidence of obesity has increased along with increased genetic predisposition to diabetes [5]. Even though mortality due to CVD is falling in Europe, it is second only to cancer in terms of morbidity and mortality worldwide. CVD is responsible for $45 \%$ all deaths in the Europe and is the main cause of death in men in all but 12 countries of Europe and in women in all but two countries in Europe. 3.9 million People die because of CVD in Europe and 1.8 million in EU [3]. This means that the number of deaths every year is almost one-fourth of new diagnosed cases 
every year. The increased incidence of CVS has also led to a higher diseased generation.

\section{Pathogenesis Of CVD}

The primary causative factor in the disease process of coronary artery disease is atherosclerosis. Atheromas are formed in wall of arteries due to gradual deposit of fatty material. These cause luminal narrowing of arteries leading to decreased supply of oxygen-rich blood to the heart [4]. Plaques can be classified into - fatty, calcific and mixed. These are not an outcome of ageing phenomenon and in fact the most common coronary plaque i.e. coronary calcium, has been classified by AHA as type $\mathrm{Vb}$ atherosclerosis [6-8]. Several studies have emphasized on the significance of coronary calcium in relation to future coronary artery disease/CVD. Coronary calcium has shown to be a better predictor of future CVD than the electrocardiogram, echocardiography, stress echocardiography etc. Calcium score is also independent of dyslipidemia in prognostication of CVD [915]. The ability of vulnerable plaques to cause severe heart attack leading to increased morbidity and mortality in recent decades has been well documented [16]. Vulnerable plaques are lipid rich, show positive remodeling, have spotty calcification and show napkin ring sign on CTCA. Traditionally Framingham risk score has been used for prediction of CVD in various populations. It is the largely a function of age \& sex and is outdated in the presence of present knowledge of CVD. Broadly speaking Framingham risk score says that treat all men aged 60 years and don't treat any women till they are 60 years [17]. This leads to considerable overlap between patients at risk and not at risk of CVD events.

\section{Cost of CVD}

CVD has been attributed to be the largest cause of mortality and morbidity and premature death along with reduced quality of life for the citizens of EU by the Council of Ministers of the European Union [18]. Coronary artery disease and cerebrovascular disease account for majority of CVD related deaths [19]. CVD is estimated to cost EU economy approximately 210 billion euros a year. This includes 111 billion euros (around 53\%) in health care costs, 54 billion euros (approx. 26\%) due to productivity losses and 45 billion euros (approx. 21\%) due to informal care of the people with CVD [3]. The healthcare expenditure includes: primary care, accident \& emergency (A\&E) care, hospital patient care, outpatient care and medications. Primary care includes CVD related visits to general practitioners (GPs), together with GPs visits to patients homes and where available visits to or by primary care nurse. Specialist consultations taking place in out-patient wards, clinics or patient's homes were included in hospital outpatient care. Whereas hospital inpatient care was calculated according to the number of days in hospital including both case admissions and rehabilitation sessions. Various trivial expenses like patient travel costs, out of pocket expenses (eg. Child care, home aids and over the counter medication) were clubbed under non-heath service costs [20]. Similarly cost of CVD in USA \& Canada is estimated to be approx. 296 billion euros \& 21.2 billion dollars respectively [21,22]. The population of EU is 510.1 million [23], which make the cost of CVD as more than 411.6 euros per person per year. On per capita basis this is even more than cost of cancer to the EU and Europe as a whole [24].

\section{Taking Inspiration From Other Successfully Implemented Screening Programs}

One of the most successfully implemented healthcarescreening programs in the world has been the various Breast Cancer Screening program. Various studies conducted in various countries have highlighted the survival \& quality of life benefits of these programs [25-27]. These studies range from being published in 1991 to 2016 show that a properly planned breast cancerscreening program is beneficial for more than 25 years. One of the primary reasons behind the successful implementation of these programs has been careful selection of screening population along with regular assessment of the program characteristics. These programs have constantly evolved/ modified over time based on the results of previous years. The screening population has been changed multiple times in various countries to make the programs more cost-effective as well as maintaining their healthcare benefit [25-27]. One of recent study published the economic analysis of the breast cancer-screening program. This study aimed at analyzing the cost-utility analysis of breast cancer screening program over a 20year period considering its utility accounting for the breast cancerscreening period between the ages of 50-70 years. Quality-adjusted life year/s was calculated. The authors found that even in the worstcase scenario the screening program proved to be beneficial [28]. Considering the increasing incidence of CVD inspiration should be taken from successfully implemented breast cancer-screening program to propose a similar computed tomography coronary angiography screening (CTCA) program for high-risk population.

\section{Role of Statins And Ideas For Further Pharmaceutical Research}

Recently the head of a prominent cardiac association aged 52 years suffered a heart attack and was diagnosed with a blocked coronary artery [29]. He is likely to have followed the guidelines of cardiac association but suffered a heart attack due to high genetic predisposition. Studies have shown that fatty and/or mixed plaques can be reduced upto $30 \%$ in size by use of high-dose statins [30,31]. Even a mild plaque has a 6 times higher mortality for patients with triple vessel involvement [32-38]. This is where the role of a wellplanned screening program becomes imperative. The aim is to identify asymptomatic individuals at risk. Asymptomatic high-risk individuals who are detected with non-significant coronary plaques can be treated using statins to decrease the plaque load.

\section{Cost of Prospected Screening Program}

A major factor involved in implementing any healthcare screening is financial cost. With a population of 743.1 million in Europe the cost of any screening program is expected to be high. However if a screening program is exquisitely planed and properly 
executed can lead to long-term decrease not only in mortality \& mortality caused due to CVD but the financial cost of CVD also. It may be important to note here that even if the cost of implementing a screening program equals the reduction in cost of CVD, the addition of life years and quality of life will be worth the effort. The cost of running a CVD screening program including Cardiac CT study shall include - cost of equipment (optimum CT scanners), qualified radiologists, adequately trained technicians and other supporting staff. Considering the variables involved the easiest to implement is coronary calcium scoring of high-risk individuals. A satisfactory coronary calcium score can be done on a 16-slice CT scanner [39]. Many studies have shown the role of vulnerable fatty/ mixed plaques in younger high-risk population. The CVD caused as a result of vulnerable plaque cause higher morbidity and mortality [40]. These plaques are not detected on CT coronary calcium study and require contrast-enhanced angiography study to optimum quantification. Therefore rather than CT calcium scoring study a CTCA study would be more beneficial for this group of population.

The screening test needs to be - fast, reliable, accurate and non-invasive. It should rule out CAD, aid in diagnosis (extent \& severity and anatomical \& flow limiting), predict outcome, guide management and exclude non-cardiac causes of chest pain. One of the salient benefits of CTCA is its high negative predictive value. A person diagnosed with a normal CTCA study is practically not susceptible to a heart attack for next few years [41,42]. This can help to segregate the screening population further such that a person with a normal CTCA study can be excluded from another CTCA for a certain period to reduce the cost of screening program. CTCA can diagnose completely occluded ramus intermedius, which is missed on catheter angiography and is even better for chronic total occlusions because of better visualization of collaterals. CTCA can help in treatment management for intervention by telling calcification, lesion length, blunt stump, bending and kinking $[43,44]$. Various software's are available which help reduce interobserver variability in detection and quantification of vulnerable plaques [45-48]. CTCA can also provide information regarding myocardial ischemia and cardiomyopathies [49-52]. Studies have proved that only ischemia guided revascularization improves survival [53].

So if the level of risk as per CTCA is:

a) Very low - the patient just needs to be reassured,

b) Low - active prevention is required,

c) High - catheter angiography with possible stent placement is suggested,

Intermediate/non-assessable-stress/ischemia imaging should be carried out.

Traditional catheter angiography is not effective in using as screening tool. CTCA can now be effectively called as gate-keeper to catheter angiography laboratory. "Of all the forms of inequality, injustice in health is the most shocking and inhumane." - Martin Luther King.

\section{References}

1. Non-calcific plaques form the majority of plaques and non-calcific \& mixed.

2. https://www.bhf.org.uk/heart-health/conditions/cardiovasculardisease.

3. European Society of Cardiology fact sheet.

4. http://www.ehnheart.org/cvd-statistics.html.

5. Stary HC, Chandler AB, Dinsmore RE, Fuster V, Glasgov S (1995) A definition of advanced types of atherosclerotic lesions and a histological classification of atherosclerosis. A report from the Committee on Vascular Lesions of the Council on Arteriosclerosis, American Heart Association. Circulation 92: 1355-1374.

6. Lee MS, Shah N (2016) The impact and pathophysiologic consequences of coronary artery deposition in percutaneous coronary interventions. The J Invasive Cardiol 28(4): 160-167.

7. McEvoy JW, Blaha MJ, DeFilippis AP, Budoff MJ, Nasir K, et al. (2000) Coronary artery calcium progression: An important clinical measurement?. JACC 56(20): 1613-1622.

8. Rumberger JA, Simons DB, Fitzpatrick LA (1995) Coronary artery calcium area by electron-beam computed tomography and coronary atherosclerotic plaque area: a histopathologic correlative study. Circulation 92(8): 2157-2162.

9. Sangiorgi G, Rumberger JA, Severson A, Edwards WD, Gregoire J (1998) Arterial calcification and not lumen stenosis is highly correlated with atherosclerotic plaque burden in humans: a histologic study of 723 coronary artery segments using non-decalcifying methodology. JACC 31(1): 126-133.

10. Youssef G, Budoff MJ (2012) Coronary artery calcium scoring, what is answered and what questions remain. Cardiovas Diagn Thar 2(2): 94105.

11. Seth SM, Blaha MJ, Blankstein R, Agatston A, Rivera JJ, et al. (2014) Dyslipidemia, coronary artery calcium and incident atherosclerotic cardiovascular disease. Circulation 129(1): 77-86.

12. Oudkerk M, Stillman AE, Halliburton SS, Kalender WA, Mohlenkamp S, et al. (2008) Coronary artery calcium screening: current status and recommendations from the European Society of Cardiac Radiology and North American Society for Cardiovascular Imaging. Int J Cardiovasc Imaging 24(6): 645-671.

13. Yeboah J, McClelland RL, Polonsky TS (2012) Comparison of novel risk markers for improvement in cardiovascular risk assessment in intermediate-risk individuals. JAMA 308(8): 788-795.

14. Detrano R, Guerci AD, Carr J, Bild DE, Burke G, et al. (2008) Coronary calcium as a predictor of coronary events in four racial or ethnic groups. NEJM 358: 1336-1345.

15. Lin FY, Shaw LJ, Dunning AM, Labounty TM, Choi JH, et al. (2011) Mortality risk in symptomatic patients with non-obstructive coronary artery disease: a prospective 2 -center study of 2583 patients undergoing 64-detector row coronary computed Tomographic angiography. J Am Coll Cardiol 58(5): 510-519.

16.https://www.framinghamheartstudy.org/risk-functions / cardiovascular-disease/10-year risk.php.

17. Council of the European Union (2004) $2586^{\text {th }}$ Council MeetingEmployment, Social Policy, Health and Consumer Affairs. 
18. Peterson S, Peto V, Rayner M, Leal J, Luengo Fernandez R, et al. (2005) European Cardiovascular Disease Statistics. London: British Heart Foundation.

19. Leal J, Luengo Fernandez R, Gray A, Peterson S, Rayner M (2006) Economic burden of cardiovascular diseases in the enlarged European Union. Eur Ht Jrl 27(13): 1610-1619.

20. American Heart Association (2005) Economic cost of cardiovascular diseases. Heart disease and Stroke Statistics.

21. Tarried JE, Lim M, DesMeules M, Luo W, Burke N, et al. (2009) A review of the cost of cardiovascular disease. Can J Cardiol 25(6): 195-202.

22. Eurostat - Population on $1^{\text {st }}$ January 2016.

23. Luengo Fernandez R, Leal J, Gray A, Sullivan R (2013) Economic burden of cancer across the European Union: a population-based cost analysis. The Lancet Onco 14(12): 1165-1174.

24. Marmot MG, Altman DG, Cameron DA, Dewar JA, Thompson SG, et al. (2013) The benefits and harms of breast cancer screening: an independent review. Br J Cancer 108(11): 2205-2240.

25. Massat NJ, Diben A, Parmar D, Cuzick J, Sasieni PD, et al. (2016) Impact of screening on breast cancer mortality: The UK program 20 years on. Cancer Epi, Biomark \& Prev 25(3): 455-462.

26. Haes JCJM, Koning HJ, Oortmarssen GJ, Agt HME, Bruyn AE, et al. (1991) The impact of a breast cancer screening programme on quality-adjusted life-years. IJC 49(4): 538-544.

27. Morton R, Sayma M, Sura MS (2017) Economic analysis of the breast cancer screening program used by the UK NHS: should the program be maintained?. Breast Cancer 9: 217-225.

28. http://nationalpost.com/news/heart-association-president-has-heartattack-during-heart-health-conference

29. Bedi U, Singh M, Singh P, Molnar J, Khosla S, et al. (2011) Effects fo statins on progression of coronary artery disease as measured by intravascular ultrasound. J Clin Hypertens 13(7): 492-496.

30. Bittencourt MS, Cerci RJ (2015) Statin effects on atherosclerotic plaques: regression or healing? BMC Med 13: 260.

31. Motoyama S, Ito H, Sarai M, Kondo T, Kawai H, et al. (2015) Plaque characterization by coronary computed tomography angiography and the likelihood of acute coronary events in mid-term follow-up. JACC 66(4): 337-346.

32. Hadamitzky M, Achenbach S, Al Mallah M, Berman D, Budoff M, et al. (2013) Optimized prognostic score for coronary computed tomographic angiography: results from the CONFIRM registry (Coronary CT angiography evaluation For clinical outcomes: an International multicenter registry). J Am Coll Cardiol 62(5): 468-476.

33. Davies MJ (1995) Stability and instability: two faces of coronary atherosclerosis. The Paul Dudley White Lecture. Circulation 94(8): 2013-2020.

34. Ambrose JA, Tannenbaum MA, Alexopoulos D, Hjemdahl Monsen CE Leavy J, et al. (1988) Angiographic progression of coronary artery disease and the development of myocardial infarction. JACC 12(1): 5662.

35. Little WC, Constantinescu M, Applegate RJ, Kutcher MA, Burrows MT, et al. (1988) Can coronary angiography predict the site of a subsequent myocardial infarction in patients with mild-to-moderate coronary artery disease? Cir 78: 1157-1166.

36. Nobuyoshi M, Tanaka M, Nosaka H, Kimura T, Yojoi H, et al. (1991) Progression of coronary atherosclerosis: is coronary spasm related to progression? J Am Coll Carciol 18(4): 904-910.
37. Giroud D, Li JM, Urban P, Meier B, Rutishauser W (1992) Relation of the site of acute myocardial infarction to the most severe coronary arterial stenosis at prior angiography. Am J Cardiol 69(8): 729-732.

38. Blaha MJ, Silverman MG, Budoff MJ (2014) Is there a role for coronary artery calcium scoring for management of asymptomatic patients at risk for coronary artery disease?: Clinical risk scores are not sufficient to define primary prevention treatment strategies among asymptomatic patients. Circ: CV Imaging 7: 398-408.

39. Park HB, Heo R, Hartaigh B, Gransar H, Nakazato R, et al. (2015) Atherosclerotic plaque characteristics by CT angiography identify coronary lesions that cause ischemia: a direct comparison to fractional flow reserve. J Am Coll Cardiol Img 8(1): 1-10.

40. Meijboom WB, Meijs MFL, Schuif JD, Cramer MJ, Mollet NR, et al. (2008) Diagnostic Accuracy of 64-slice Computed Tomography Coronary Angiography. JACC 52(25): 2135-2144.

41. Budoff MJ, Dowe D, Giter M, Sutherland J, Halamert E, et al. (2008) Diagnostic performance of 64-multidetector row coronary computed tomographic angiography for evaluation of coronary artery stenosis in individuals without known coronary artery disease: results from the prospective multicenter ACCURACY (Assessment by Coronary Computed Tomographic Angiography of Individuals Undergoing Invasive Coronary Angiography) trial. JACC 52(21): 1724-1732.

42. Stephan Achenbach (2014) CTCA can diagnose completely occluded ramus intermedius which is missed on cath. Even better for chronic total occlusions because of better visualization of collaterals. SCCT.

43. Magro M, Schultz C, Simsek C, Garcia Garcia HM, Regar E, et al. (2010) Computed tomography as a tool for percutaneous coronary intervention of chronic total occlusions. Euro intervention 6 Suppl G: G123-31.

44. Maurovich Horvat P, Ferencik M, Voros S, Merkely B, Hoffman U (2014) Comprehensive plaque assessment by coronary CT angiography. Nat Rev Cardiol 11(7): 390-402.

45. Bom MJ, Heijden DJvd, Kedhi E, Heyden Jvd, Meuwissen M, et al. (2017) Early detection and treatment of the vulnerable coronary plaque: Can we prevent acute coronary syndromes? Cir: Card Imag 10(5).

46. Fujimoto S, Kondo T, Daida H (2014) Plaque evaluation by coronary CT angiography. J Jpn Coron Assoc 20: 273-281.

47. Ho KT, Chua KC, Klotz E, Panknin C (2010) Stress and rest dynamic myocardial perfusion imaging by evaluation of complete timeattenuation curves with dual-source CT. J Am Coll Cardiol Img 3(8): 811820 .

48. Schwarz F, Bamberg F, Becker CR (2010) Dynamic myocardial stress perfusion. Somatom Session Siemens Healthcare Germany.

49. Ho KT, Chua KC, Klotz E, Panknin C (2010) CT dynamic myocardial stress perfusion imaging - correlation with SPECT. Somatom Session Siemens Healthcare Germany.

50. Feuchtner G, Goetti R, Plass A, Wieser M, Scheffel H, et al. (2011) Adenosine stress high-pitc 128-slice dual-source myocardial computed tomography perfusion for imaging of reversible myocardial ischemia. Circ Cradiovasc Imaging 4: 540-549.

51. Hachamovitch R, Hayes SW, Friedman JD, Cohen I, Berman DS (2003) Comparison of the short-term survival benefit associated with revascularization compared with medical therapy in patients with no prior coronary artery disease undergoing stress myocardial perfusion single photon emission computed tomography. Circulation 107(23): 2900-2907.

52. Patel MR, Peterson ED, Dai D, Brennan JM, Redberg RF, et al. (2010) Low diagnostic yield of elective coronary angiography. N Eng J Med 362(10): 886-895. 
(c) (i) This work is licensed under Creative

To Submit Your Article Click Here:

Submit Article

DOI: $10.32474 /$ ACR.2018.01.000108

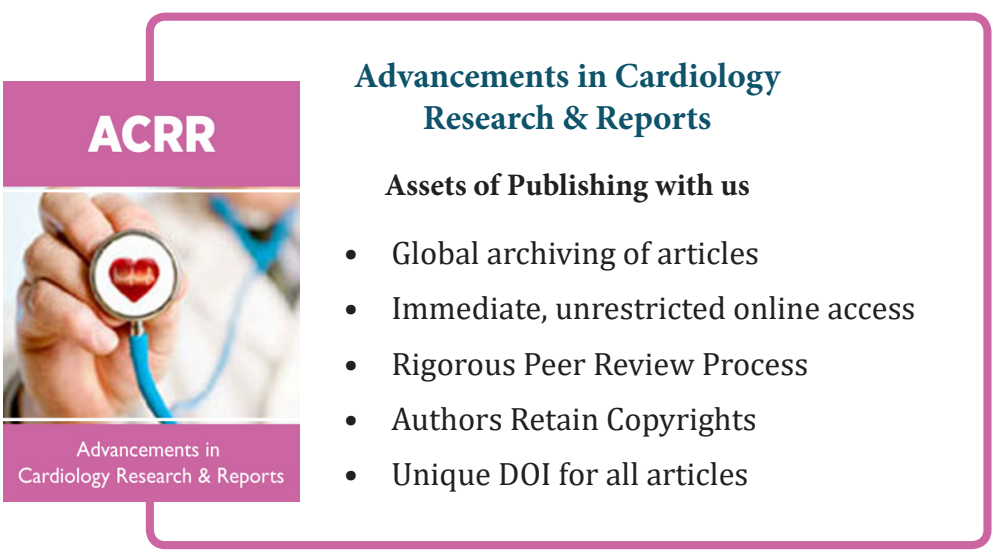

